\title{
Lessons not yet learned from the Fukushima disaster
}

\author{
Jens-Uwe Klügel
}

Received: 4 October 2014 / Accepted: 4 November 2014 / Published online: 6 December 2014 (C) Akadémiai Kiadó 2014

\begin{abstract}
The Fukushima nuclear catastrophe has led to a wide-spread international discussion on how seismic and tsunami hazards can be better predicted and adverse consequences be prevented. In some countries the event led to the complete phase-out of nuclear energy. The lessons drawn by different organisations including earth scientists, earthquake engineers, non-governmental and governmental organisations will be reviewed from an independent position. This review captures the following areas: (1) Hazard assessment, (2) Engineering design and defence in depth concepts, (3) Emergency preparedness. It is shown that not all important lessons from the catastrophe have been drawn, because some of the root causes of the accident are not yet addressed. Especially the need of a holistic approach towards hazard assessment and the implementation of defence in depth and diversity of design principles for critical infrastructures like nuclear power plants hast to be stronger emphasized to prevent similar disasters.
\end{abstract}

Keywords Disaster prevention · Seismic hazard analysis · Tsunami hazard analysis

\section{Introduction}

The nuclear catastrophe of Fukushima triggered an intense discussion about the safety of nuclear power plants. As an immediate consequence many countries requested to perform safety and security stress tests. In addition or as a consequence of stress test results the implementation of urgent measures to improve nuclear power plant safety were requested by regulatory agencies. Actions taken were frequently copied from one country to the other a not unusual activism observed after big accidents to quieten public opinion. The sequence of events has been analysed in detail both by expert organisations (GRS 2013) as well as by

\footnotetext{
J.-U. Klügel $(\varangle)$

NPP Goesgen-Daeniken, Daeniken, Switzerland

e-mail: jkluegel@msn.com

J.-U. Klügel

International Seismic Safety Organisation (ISSO), Arsita, Italy
} 


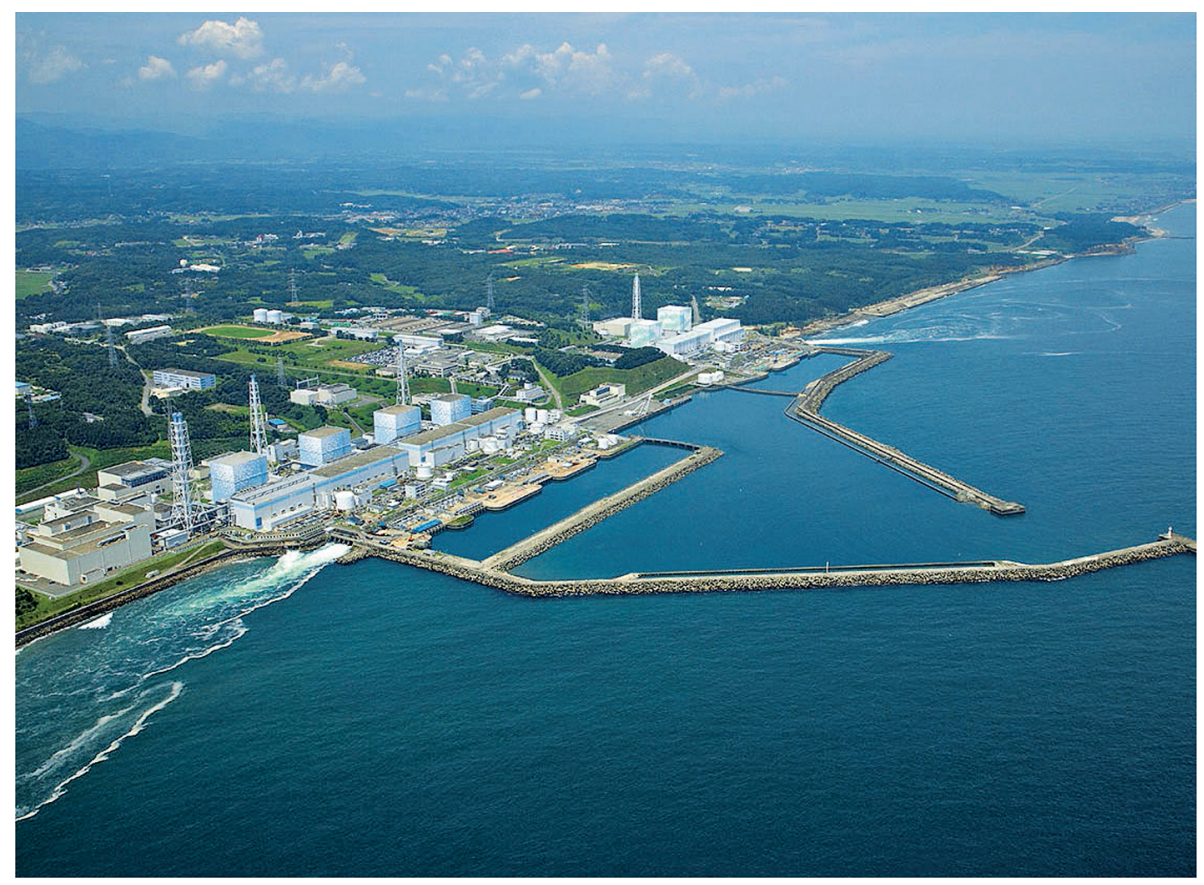

Fig. 1 Fukushima nuclear power plant site (Tokyo electric power company)

critical non-governmental organisations (Lochbaum et al. 2013). Nevertheless a systematic and in depth analysis of the root causes of the accident is not easily be found. Without such a root cause analysis it is difficult to judge whether the actions taken or planned will really prevent similar catastrophes in the future.

This paper is attempting to provide this missing root cause analysis by separating important causes from contributing factors that had some but not decisive effect on the final consequences of the Fukushima accident. Based on the root cause analysis an evaluation is performed whether the actions taken by different national and international organisations are satisfactory to prevent future nuclear disasters or what additional actions may have to be required.

\section{Summary of the Fukushima accident sequence}

The sequence of events leading to the nuclear catastrophe of Fukushima is described in detail in (GRS 2013) or similar reports issued by different organisations (IAEA 2011; INPO 2011). Here we provide a short summary about the key events leading to the core damage in 3 nuclear reactors. Figure 1 shows the Fukushima Nuclear Power Plant site before the accident. Figure 2 shows the allocation of buildings at the site area.

The accident was triggered by the big Tohoku-Oki earthquake at 14:46 local time on March, 11,2011 . This subduction earthquake with a moment magnitude $\mathrm{M}_{\mathrm{w}}$ of 9.0 is assessed as of being the largest earthquake observed in historical time in Japan. The earthquake hypocentre was located at a depth of $30 \mathrm{~km}$ below sea ground approximately $130 \mathrm{~km}$ east of Sendai. The earthquake led to a large horizontal displacement of $15 \mathrm{~m}$ and a vertical displacement of about $9 \mathrm{~m}$ at sea ground level. 


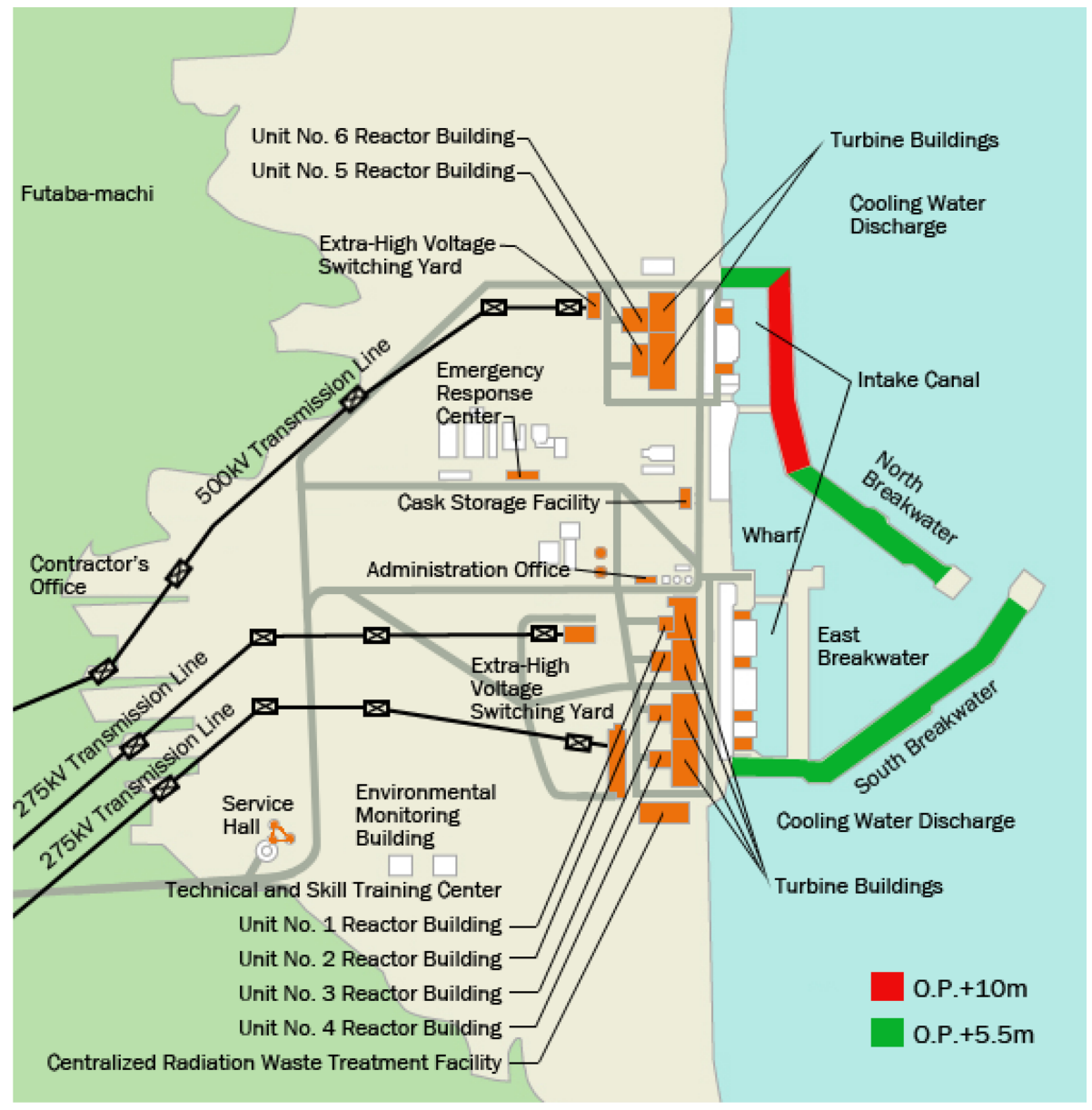

Fig. 2 Fukushima nuclear power plant site—allocation of buildings (INPO 2011)

The earthquake caused all of the operating units (units 1,2, and 3) at the Fukushima site to automatically scram on seismic reactor protection system trips. It is worth to mention that only few nuclear power plants in the World (Japanese, Russian, and Bulgarian) possess such seismic shutdown systems. The earthquake damaged breakers and distribution towers, causing a loss of all off-site electrical power sources to the site. The emergency diesel generators (2 per unit) automatically started and provided AC power to emergency systems. At this point of time all plants were in a safe transition state to cold shutdown.

At 14:49 a first tsunami alert was issued. The predicted expected height was $3 \mathrm{~m}$ that is below the tsunami design of the Fukushima nuclear power plants. Forty-one minutes after the earthquake, at 15:27, the first of a series of seven tsunamis arrived at the site. The maximum tsunami height impacting the site was estimated to be 14-15 m. This exceeded the design basis tsunami height of $5.7 \mathrm{~m}$ and was above the site grade levels of $10 \mathrm{~m}$ at units $1-4$ (Fig. 3).

As a consequence of the arrival of the tsunami waves all water intakes of units 1-4 failed and at 15:51 the diesel generators of the units failed. Thus the AC power supply completely failed. A total station blackout (loss of all AC power supplies) occurred. Additionally the 


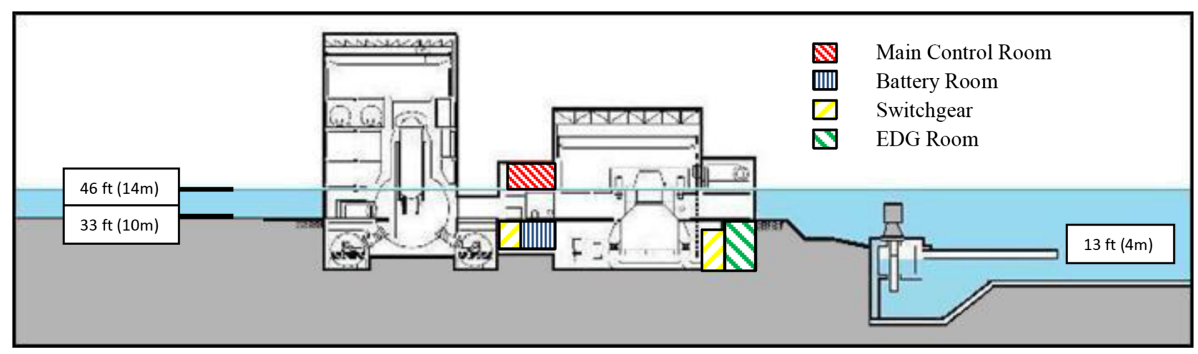

Fig. 3 Inundation levels after arrival of tsunami waves (height $14 \mathrm{~m}$ ) (in blue the tsunami water level)

batteries at unit 1 failed because the battery room was flooded. The present generation of nuclear power plants are not designed to withstand a long term total station blackout. Such extreme beyond design basis accidents are coped with by prepared accident management actions requesting manual interference of plant operators. If these actions are performed successfully the consequences of a long term station blackout can be mitigated. It is important to note that accident management actions carried out at the plant site always require external support (human resources, technical means, and specialized equipment) at the long term. Due to the tremendous damage caused by the earthquake and the tsunami failing the regional infrastructure more or less completely and killing many people such external support was not available despite the fact that the plant staff was able to delay the core damage for units 3 and especially unit 2 substantially. Nevertheless the core damage could not be prevented. Despite that many details of the accident progression are not yet fully clarified it has to be concluded that core damage at unit 1 started around $4-5 \mathrm{~h}$ after the earthquake. In unit 2 the core damage most likely occurred during the evening hours of March 14, 2011, while in unit 3 the core damage started most likely in the morning hours of March 14, 2014 (GRS 2013). Without external support the subsequent consequences including radiological releases could not be prevented.

\section{Direct and root causes of the accident}

For learning lessons from a nuclear disaster it is important to understand the key direct and especially the key root causes of the accident. The first reflective actions taken after the accident in many countries were related to an improvement of accident management. These actions were taken even without detailed analysis. It can be concluded that the main cause for the accident was considered to be an insufficiently prepared accident management. A closer look shows that this is not true. The main reason is that a long term accident management is only possible if at least a long term external support is possible. In case of such an extreme hazard like in Fukushima which is affecting a whole region this is unlikely to be expected. Some operators of nuclear power plants argued (as it is frequently done on such occasions) that such an event cannot happen here ("Not here", see for example for the U.S. the discussion in Lochbaum et al. (2013). This argument may be valid with respect to the very specific combinations of hazards affecting Fukushima. It is generally not true with regard to the possible occurrence of extreme events of natural origin that may affect the plant. Therefore, a deeper look at the root causes is required.

The following areas have to be considered:

(1) Hazard analysis 
(2) Engineering design and good practices

(3) Emergency preparedness

\subsection{Hazard analysis}

The tsunami design levels were based on the observation of tsunami heights after the Great Chile Earthquake of 1960. Therefore the original tsunami design of the plant considered a wave height of about 3.1-3.7 m. An evaluation performed in 2002 ended up with a revised hazard estimate of 5.1-5.2 $\mathrm{m}$ still within the scope of safety provisions of the plant. This was confirmed by a detailed probabilistic tsunami study performed by TEPCO (Tokyo Electric Power Company) using expert judgement and the very popular in probabilistic hazard analysis logic tree approach to estimate the tsunami hazard triggered by a large subduction earthquake as it is characteristic for the Sendai coast of Japan (Annaka et al. 2007). The evaluation of the study results was based on the mean value (Annaka et al. 2007) estimated over a prediction time period of 30 years. The same study indicated the possibility of higher inundation levels that corresponded to the upper tail fractiles of the uncertainty distribution. These possible insights were ignored because the mean value of the logic was used as the decision criterion. The hazard assessment ignored to a large extent the observed historical experience of the region north of Fukushima. For instance the big Sanriku tsunami of 1896 was caused by an earthquake of magnitude 7.2 caused much higher inundation levels and the tsunami following the Jagun earthquake of 869 that struck the Sanriku area led to observable remnants far inland of the Fukushima coats region.

\subsection{Engineering design and good practices}

Even given the underestimation of the seismic and tsunami hazard the consequences of the March 11, 2011 events could have been mitigated if the plant design would have followed the generally accepted approaches of ensuring nuclear safety. The main approach for ensuring nuclear safety is the application of the "defence in depth" concept. This concept requires the implementation of several levels of defence and multiple barriers to prevent accidents or to mitigate their consequences preventing releases of radioactivity. According to INSAG (International Nuclear Safety Advisory Group)10 (International Nuclear Safety Advisory Group 1996) defence in depth has the following objectives (quotation):

- "to compensate for potential human and component failures;

- to maintain the effectiveness of the barriers by averting damage to the plant and to the barriers themselves; and

- to protect the public and the environment from harm in the event that these barriers are not fully effective."

To ensure a sufficient level of reliability of the technical means applied to achieve these objectives the principles of redundancy, functional independency (physical separation of redundancies) and diversity are applied. The principle of redundancy requires a design of the safety systems with abundant capacity provided by several channels of safety. Most typically an independent single failure is considered, requiring a $\mathrm{N}+1-$ design ( $\mathrm{N}$ channels required for complying with the required functions +1 coping with an independent from the initiating event single failure) of systems. Meanwhile it is good practice to provide a $\mathrm{N}+2$ design for safety systems taking into account an additional unavailability that may have been caused by maintenance work. What frequently is overlooked is that these principles have to be applied not only for the front line systems performing required safety functions but also for support functions ensuring the operability of the frontline systems. 
The functional independency (physical separation) shall provide some defence against events that may affect common elements of the functional chains of safety systems. At the same time it provides protection against so-called area events. These are events that may destroy equipment in a localized area. In case of a tsunami such a localized area is the near coast part of the site which is vulnerable to flood waves. Physical separation ensures that such area events cannot fail equipment belonging to different redundancies of the safety system.

The principle of diversity requires that safety functions serving the same purpose (e.g. injecting water into the reactor) are performed by systems following physically different operational principles. For example safety injection provided by a pump could be complemented by safety injection from a pressurized tank (accumulator) injection water once the pressure in the reactor drops below the pressure in the tank not requiring electrical power for its operation.

These principles were not complied with in the design of the Fukushima Daichii Nuclear Power Plant. The principle of physical separation would have required a spatial separation of the two existing diesel generators located in the turbine building below the inundation level of tsunami floods. The allocation of one of the diesel generators away from the coast for example behind the reactor building and the availability of a raised cooling water pool or well providing emergency cooling for essential safety systems most likely would have been sufficient to prevent the catastrophic consequences of the tsunami waves attacking the reactor units. Modern designs require at least an independent second main water intake and a second heat sink to ensure heat removal after a reactor shutdown. This was not fulfilled for the Fukushima plant. The loss of the main water intakeas the result of the impact of the tsunami limited the chances of an early recovery of the accident situation.

\subsection{Emergency preparedness}

The Fukushima Nuclear Power Plant was reasonably well prepared for an emergency situation. The plant possessed a dedicated emergency centre that was designed against large seismic loads and provided radiological sheltering for emergency staff. Before the Fukushima accident very few nuclear power plants had a similar facility. Additionally, the Japanese nuclear power plants have a dedicated trained emergency team although of limited staffing on the site. During the accident the staff in general did the best that could have been expected given such an extreme external event. In the aftermath (the usual hindsight) some deficiencies were discovered that affected the efficacy of accident management actions. The most important was the dependency of accident management actions on DC power (from batteries). Battery power was required to keep valves in the injection connections provided for accident management to the feedwater system open. Battery capacity in general is limited. Usually it lasts for not more than $10 \mathrm{~h}$ without charging. Significant time delays occurred because of interactions between security requirements and safety needs. Security doors under loss of offsite power conditions locked completely thus preventing or delaying access to some service areas.

It is also frequently stated that there was some lack of written guidance how to implement severe accident management actions, but the key problem while implementing accident management actions was the lack of external support. The accident sequence in unit 1 was too fast anyway, to implement counter measures but with more efficient external support a significantly better chance to mitigate the consequences of the accidents at unit 3 and 2 can reasonably be expected. Therefore the root cause for the problems encountered in the area of emergency preparedness was (is!) the widespread false belief that with a sufficient time window available efficient external support would be available in time to prevent the worst. 


\section{Actions taken by international organisations after the Fukushima accident}

After the Fukushima accident many activities were launched by different international organisations (IAEA (International Atomic Energy Agency), ENSREG (European Nuclear Safety Regulators), WENRA (Western European Nuclear Regulatory Agencies), and WANO (World Association of Nuclear Operators)) and national regulatory agencies. The activities can be subdivided into

(1) Complementary safety assessment

(2) Short term actions

(3) Long term actions

The complementary safety assessment included different types of national and international stress tests (e.g. European stress test) focussed on specific design issues like the protection against external events and on emergency preparedness including severe accident scenarios. The plant-specific assessments were performed mainly on deterministic grounds, while the hazard estimates were frequently based on probabilistic methods despite the obvious flaws of the method leading to the biased hazard estimates of TEPCO accepted by the Japanese regulator NISA (Nuclear and Industrial Safety Agency). Insights from PSA studies (Probabilistic Safety Analysis) were considered in a more qualitative sense. The low risk numbers frequently reported especially for natural hazards like earthquakes and floods including dam breaks were questioned seriously in view of the Fukushima events with the exception of the U.S.A. (Lochbaum et al. 2013).

Short term actions were mainly aimed at improvements of accident management and emergency response procedures. WANO suggested and endorsed the implementation of the so-called FLEX (shortcut for "diverse and flexible mitigation capability") strategy worldwide like it was implemented by the nuclear industry (INPO) in the U.S.A. This strategy includes the foundation of well-equipped local and/or regional emergency centres. In few countries it includes special dedicated emergency teams. Similar approaches were implemented in Russia, France and in a more limited scope in Switzerland. The implementation of this strategy included minor plant modifications like the installation of additional injection nozzles with flexible connections for fire extinguishing water hoses, the purchase and storage of additional diesel fuel reserves and the onsite storage of additional mobile pumps. These short-term actions certainly improved the NPPs (Nuclear Power Plants) capacity to execute mitigating accident management actions in case of a severe accident but they do not contribute to accident prevention.

Mid- und long term actions include the implementation of bunkered station blackout systems (e.g. Japan) or additional secured diesel generator buildings (planned in France), filtered containment venting systems and passive autocatalytic recombiners. While the later measures serve also the purpose of severe accident management the first and more expansive measures represent a design basis extension that leads to a significant reduction of risk. Only very few plants have decided to go in this direction and plan to extend their original design basis to cope with previously not considered extreme external events. The reason why the number of plants is limited is because of the problems associated with the amortization of the costs. This is difficult even in case of lifetime extension.

Some countries preferred to move to a direct phase-out of nuclear energy (Germany and Belgium, and Switzerland at least on the long term) because other competitive sources of electricity appeared to be available in Europe. 


\section{Lessons not yet learned from Fukushima}

Reviewing the actions taken by the international nuclear community it has to be concluded that only a minor part of the root causes of the Fukushima disaster is addressed. The main focus is on emergency preparedness, the least important contributor to the disaster. The most important root cause - the underestimation of the seismic and tsunami hazard-is not addressed at all. Despite the very poor hazard prediction results of traditional PSHA (Probabilistic Seismic Hazard Analysis), - nearly all recent large earthquakes (Tohoku earthquake and tsunami, Haiti (2010), Sichuan (2008), L'Aquila (2009) were underestimated in PSHA maps) the method is still in use and widely endorsed internationally although their systematic errors are very well-known as for instance is outlined in Klügel (2007, 2008, 2011). If this important lesson is not learned catastrophes like in Fukushima may repeat. They also may affect other safety critical industries. There are still many nuclear power plants located in active seismic regions. Their seismic or tsunami design basis was obtained from probabilistic hazard studies. Most likely the design of these plants is based on biased assessments. So what is wrong with the NUREG/CR-6372 method of PSHA (Senior Seismic Hazard Analysis Committee (SSHAC) 1997) originally developed by Cornell (1968)

Here I will discuss only the most important topics:

(1) The Poisson assumption and the lognormallity of site specific ground motions

(2) The false belief in "return periods"

(3) The use of logic trees and the aggregation of expert opinions

(4) The inadequacy of PSHA results for engineering damage prediction

\subsection{The Poisson assumption and the lognormallity of site specific ground motions}

The assumptions that earthquake recurrence mathematically follows a Homogeneous Poisson Process (HPP) and the assumption that the distribution of ground motion (spectral acceleration) follows a lognormal distribution provide the hard core basis of standard PSHA (Cornell 1968; Senior Seismic Hazard Analysis Committee (SSHAC) 1997). On the first look there seems to be some basis for this assumption looking at observational data. Statistical tests can be provided to support these assumptions. For earthquake recurrence it may require the elimination of some "disturbing" information by using a declustering technique.

The model of a Homogeneous Poisson Process is wrong for a very obvious reason and this reason has nothing to do with statistics but with elementary seismology and fault mechanics. A homogeneous Poisson Process is a memory less process. That means that the occurrence of an earthquake is not dependent on the occurrence of previous earthquakes. The probability that an earthquake will occur is constant for each point in space and independent of time. This property of lack of memory less of the HPP contradicts to the theory "seismic cycle" that is based on the simple physical law that a fault system that has released its energy has to rebuild strain and stress conditions that are able to trigger the next event. This process needs time. Therefore, the process of earthquake recurrence for a given point of space is time dependent. On the other hand each earthquake causes physical destruction of the geological formation (part of the fault) forming the conditions for its occurrence. These effects may be different in scale for small and for large earthquakes but they exist for both types of earthquakes. This simply means that a complete mathematical description of earthquake recurrence needs a joint, multivariate model depending on space and time:

$$
f(E)=g(t, \vec{X})
$$


Here $E$ represents the event (occurrence of an earthquake), $t$ is time and $\vec{X}$ is the location vector of the point of interest in a corresponding system of coordinates.

This characteristic behaviour is even acknowledged by proponents of PSHA like the late (Bolt 2004) who described the recurrence behaviour of earthquakes as a combination of a self-exciting and of a self-correction behaviour. The self- exciting behaviour describes the instance that an earthquake occurring at point $(\mathrm{x}, \mathrm{t} 1)$ in space and time increases the likelihood of an earthquake occurring at point $(\mathrm{y}, \mathrm{t} 2)$ in space and time, where $\mathrm{t} 1$ is less than t2. Self-correcting behaviour characterizes the circumstance that the conditional rate of an earthquake at $(y, t 2)$ depends on the strain present at point $y$ and time $\mathrm{t} 2$. As the occurrence of an earthquake at a nearby point $\mathrm{x}$ at a previous time $\mathrm{t} 1$ decreases the strain at point $\mathrm{y}$, such an event will generally decrease the conditional rate at (y, $\mathrm{t} 2)$. This description clearly leads to a model like described by Eq. (5.1) and it is obvious that this is not a recurrence model of a Homogeneous Poisson Process.

What is the reason why statistical tests (at least after declustering) frequently seem to prove the compliance with a Homogeneous Poisson Process? It is a simple statistical trick. It is well known that due to theorem of the Russian mathematician Khinchine the superposition of stochastic processes (independent from their true characteristics) asymptotically converges to a Poisson process if none of the underlying processes is dominating. This "non-dominance" property of data can be achieved by a process called data pooling. Data pooling (or the use of insufficiently classified data) is one of the statistical tricks that is frequently applied to hide functional dependencies in observational data. With regard to our problem data pooling is achieved by ignoring the dependence of earthquake frequency on spatial variables in Eq. (5.1). Hence the pooling is performed over space. PSHA recurrence models pool recurrence data from regions with low seismicity together with regions (e.g. faults) which are seismically active. As long as the area (zone in a zonation model) from where data is collected is large enough the preconditions of the theorem of Khinchine remain to be valid. Effectively active seismological nodes like active faults obtain a low weight in this pooling process due to their small dimensions or due to the large recurrence period of earthquakes at these faults extending beyond the range of the observation period. This process pooling process works also on large faults consisting of many segments. Individual earthquakes most frequently lead to a rupture of only a part of a fault or fault segment. Such active parts (segments) are pooled together with not active parts. Again the pooling assured that the theorem of Khinchine holds. Therefore we have to conclude that the results of statistical tests are intentionally or unintentionally made up. Anyway standard statistical tests do not prove anything. A positive results simply says that it cannot be excluded that the data analysed comes from a specific type of distribution. Further analysis shall be performed to check whether the selected distribution or the selected model has any physical meaning. The Poisson assumption obviously does not have such a physical meaning. The conclusion is that a Poisson model of earthquake recurrence developed on pooled data cannot be used for the prediction of future hazards for any type of local critical infrastructure because this model contradicts to the physics of earthquake recurrence.

The situation is very similar with regard to the assumption of the lognormal character of ground motions expressed by the following standard form of an Empirical Ground Motion Prediction Equation (GMPE):

$$
\log \left(S_{a}\right)=h\left(m, r, X_{\text {other }}\right)+\varepsilon \sigma_{\log }
$$

Here $S_{a}$ is spectral acceleration, $m$ is magnitude (in whatever scale), $r$ is distance (in whatever scale) $X_{\text {other }}$ are other explanatory variables used in the model $h$ describing the regression mean (Senior Seismic Hazard Analysis Committee (SSHAC) 1997) for the data used in its development; $\sigma_{\log }$ is the standard deviation in $\log$ scale and $\varepsilon$ is the normalized standard 
error obtained under the assumption that the residuals in Eq. (5.2) are normally distributed: $E=\varepsilon \sigma_{\log } \sim N\left(0, \sigma_{\log }\right)$. In PSHA (Senior Seismic Hazard Analysis Committee (SSHAC) 1997) the term E is usually interpreted as aleatory variability. Again the lognormallity is frequently approved by statistical testing. Again this is the result of data pooling. The seemingly lognormal behaviour is the result of the Central Limit Theorem applied in log space. This time the pooling is performed by lumping earthquake recordings (e.g. acceleration time histories) from different areas of the world into a common database and fitting a regression equation based on this data. Of course different shapes of such equations can be suggested and this type of modelling uncertainty is then classified as epistemic (lack of knowledge) uncertainty.

Another problem is that Eq. (5.2) assumes axisymmetric wave propagation. This assumption is only approximately valid for the far field solution of the wave propagation equation while the results of PSHA for critical infrastructures typically indicate that the probabilistic seismic hazard is governed by near field sources. Therefore the results of PSHA are in contradiction to the preconditions required to make the PSHA seismic wave attenuation model at least asymptotically applicable.

The next question is whether the results of a PSHA have any meaning for practical risk assessment of a critical infrastructure. Here we are looking only on the formal mathematical part of the question. The standard PSHA model for hazard integration over all possible seismic sources looks like the following equation generalized from (Reiter 1990):

$$
E(a)=\sum_{i=1}^{N} v_{i} \int_{m_{0}}^{m_{u}} \int_{r=0}^{\infty} f_{i}(m) f(r \mid m)_{i} P_{i}\left(S_{a}>a \mid m, r\right) d r d m
$$

Here $E(a)$ is the expected number of exceedances (the mean annual rate of exceedances, the annual frequency of exceedance) of ground motion level $a$ during time $t$ ( 1 year for the annual rate), $v_{i}$ is the mean rate of occurrence of earthquakes between lower and upper magnitude bounds $\left(m_{0}\right.$ and $m_{u}$ ) being considered for the $i$-th source, $f_{i}(m)$ is the probability density distribution of magnitude (recurrence relationship) within source $i, f(r \mid m)_{i}$ is the conditional probability density distribution of epicentral (or source) distance between various locations within source $i$ and the site (reference point) for which the hazard is being estimated and $P_{i}\left(S_{a}>a \mid m, r\right)$ is the conditional probability that a given earthquake of magnitude $m$ and distance $r$ to a point in source $i$ will exceed ground motion level $a$. This probability is typically computed using an Empirical Ground Motion Prediction Equation:

$$
P_{i}\left(S_{a}>a \mid m, r\right)=\Phi^{\prime}\left(\frac{\log \left(S_{a}\right)-h_{i}(m, r)}{\sigma_{\log , i}}\right)
$$

Here it is assumed that a separate GMPE is available for each of the sources. That would be the best way of performing a PSHA study allowing to consider directly source and path dependencies, but most frequently just a single equation is used for all the sources and different alternatives are investigated using a logic tree approach.

The point to be emphasized here is that the location of the site of the critical infrastructure is assumed to be a point. The problem is that the hazard assessed based on this assumption is significantly underestimating the risk for the critical infrastructure. A typical nuclear power plant (single unit) has an area of between 50,000 and 100,000 $\mathrm{m}^{2}$. This can hardly be approximated as a point. Of course the acceleration levels will differ over such an area (e.g. seismic wave incoherency, different local soil properties) but it is unlikely that the acceleration levels will differ by so much that they do not impose any risk for plant equipment. The key point is that the frequency of exceedance is computed wrongly because it would be necessary to 
perform the evaluation of the frequency over the whole area of the plant (over a large amount of points) not just for a reference point.

The events of Fukushima indicated an even larger problem. The Fukushima site was not the site most affected by the Tohoku-Oki earthquake. Significantly higher intensity levels were observed outside of Fukushima NPP. Nevertheless, the damage caused by the earthquake in other places heavily affected the safety of the Fukushima NPPs. This external to the site damage caused the loss of offsite power (unavailability of the electrical grid) as well as of the long term inaccessibility of the plant for external support forces. It also bound resources of the Japanese Self Defence Forces so that they could not support the plant staff in mitigating the consequences of the accident (Lochbaum et al. 2013).

In summary it can be concluded that the key assumptions used in PASHA (Senior Seismic Hazard Analysis Committee (SSHAC) 1997) are incorrect. The results obtained by PSHA are insufficient to address the full scale of possible damaging effects influencing the safety of a critical infrastructure like a nuclear power plant. Such damaging effects may occur much more likely than calculated by PSHA especially in high seismic regions like California (e.g. for the NPP Diablo Canyon) and Japan.

\subsection{The false belief in "return periods"}

Based on the Poisson assumption it is common to define a "return period" for an earthquake corresponding to a specific acceleration level. Many national seismic civil engineering codes are based on this terminology. The derivation of "return period" is based on the assumption that the frequency of occurrence of an earthquake is constant with time. Under the Poisson assumption the probability that an earthquake exceeding acceleration level $a$ will occur within time period $t$ is:

$$
p=1-\exp (-E(a) t)
$$

According to terminology the return period $\mathrm{T}$ is defined as the reciprocal value of the frequency of an earthquake exceeding acceleration level $a$ :

$$
T=\frac{1}{E(a)}
$$

For $t=1$ year and $E(a) \ll 1$ we can develop the right term of Eq. (5.5) into a series disregarding the higher terms and obtain:

$$
p \approx E(a) t=E(a) \times 1 \text { year }=\frac{1}{T} \times 1 \text { year }
$$

Therefore, numerically the "return period" is the reciprocal value of the probability that an earthquake exceeding acceleration level $a$ will occur within one year. It is obvious that this derivation of the "return period" is valid only under the Poisson assumption. The danger of the term "return period" is that people started to believe that a "return period" is a temporal characteristic of earthquake recurrence. Therefore, people and especially engineers and regulatory decision makers started to believe that a "return period" of 10,000 years really means that earthquakes exceeding an acceleration level corresponding to $a$ will occur only once in 10,000 years.

This is not correct for manifold reasons.

First of all as shown before the Poisson assumption is physically not valid for earthquake recurrence (Sect. 5.1). Secondly, the analysis of Eq. (5.3) shows that only the average rate of events $v_{i}$ (number of earthquakes originated in source) above the minimal magnitude level 
taken into account) and the magnitude recurrence relationship are directly related to a frequency). All other terms are spatial characteristics. Especially the probability of exceedance calculated by Eq. (5.4) plays the role of a "spatial reduction factor", because its values is $\leq 1$. Its calculation is based on empirical GMPE that are based on the assumption axisymmetric wave propagation. Therefore, the number (frequency) of earthquakes that potentially endanger the site of a critical infrastructure is much higher than the predicted mean value $E(a)$. Because each of these earthquakes affects a shaking area that is much larger than just a point and because the assumption of axisymmetric wave propagation in general is not valid, it has to be expected that for a significant number of points at distance $r$ from the source of the earthquake the frequency of exceeding $a$ is significantly higher than the predicted mean value. Statistically the fraction of this points could be assessed by using the higher fractiles of the uncertainty distribution for the ground motion levels given by the GMPE (frequently called the aleatory variability distribution) if the GMPE were verified and validated. This is very important for probabilistic seismic hazard maps that are usually based on the median (then in $50 \%$ of all points located at distance $r$ from the source a deviation from the prediction is expected) or the mean value of the hazard. But here the next (third problem) arises. In regions with lack of observational data empirical GMPEs are imported from other regions. In many cases the GMPEs are derived from data collected in different regions (ergodic assumption observations in time at a single station (long term observation) are replaced by observations at many stations (space, short term observations)) that are pooled together. Therefore, these equations may not even reflect the true "spatial" behaviour of seismic wave propagation. That introduces an additional source of error into the analysis.

Summarizing the discussion it has to be concluded that the term "return period" does not represent a temporal characteristic of earthquake recurrence. It is a nice surrogate (many "real" earthquakes are replace by the model of a single Poisson type earthquake) term invented for illustration but completely without any temporal meaning. Dangerous earthquakes happen much more frequently than predicted by these maps. It is very natural that probabilistic seismic hazard maps are not able to predict future hazards and that empirical earthquake observations show significant deviations from such maps.

\subsection{The use of logic trees and the aggregation of expert opinions}

The U.S NRC (Nuclear Regulatory Commission) recognized the complexity of seismic hazard assessment and most likely came to the conclusion that a realistic seismic hazard assessment is not possible due to the manifold problems to be solved. Therefore, they came up with the idea to develop a "scientific consensus" on the seismic hazard of critical infrastructures and developed a formalised approach to utilize logic trees and expert judgement to obtain consensus models that reflect the centre, the body and the range of opinion of the technical informed community with respect to the seismic hazard assessment of critical nuclear infrastructures (Senior Seismic Hazard Analysis Committee (SSHAC) 1997). Therefore, the main goal is to achieve a harmonized view on the seismic hazard to be considered and not to obtain a realistic seismic hazard estimate. From the point of view of politics and democratic formation of a societal opinion this approach may be regarded as reasonable. Unfortunately, science is not following the rules of democracy and history of science has proven that the scientific main stream was frequently wrong.

The key technique employed is the weighing of different modelling alternatives by the use of logic trees. Models have to be developed or proposed by experts in a facilitated expert judgement process. In this process the experts assess (weigh) the scientific validity of the different models proposed by assigning weights (subjective probabilities) reflecting their 
degree of belief in the corresponding models. Different levels of expert judgement processes are defined with level 4 being the highest level (Senior Seismic Hazard Analysis Committee (SSHAC) 1997; Ayyub and Klir 2006). In a level 4 process the experts have the right to overrule observation and measurement data (Abrahamson et al. 2004) and they stay the owners of their models. The later means that nobody has the right to correct their results. Only earth scientists (with very limited knowledge of nuclear technology) are allowed to participate in the assessment process.

In Klügel (2011) I provided a detailed review of the associated methods. It was clearly demonstrated that the results of these methods are ambiguous. The formal mathematical aggregation of expert opinions can be performed using different techniques e.g. equal weights for each expert, performance based weights, Bayesian aggregation (geometric weights) etc. It was shown that for the same seismological and geological input the results of hazard integration will be very different in dependence on the mathematical aggregation method used.

Therefore, the use of logic trees and of expert judgement does not help to obtain realistic hazard assessments. Therefore, it also does not help to prevent the repetition of disasters caused by extreme natural events as observed in Fukushima.

\subsection{The inadequacy of PSHA results for engineering damage prediction}

The main result of a PSHA is the so-called uniform hazard spectrum (UHS) of ground motion acceleration (Abrahamson et al. 2004) although some alternatives based on the disaggregation of the spectrum are applied in research applications. A UHS is compiled of computed spectral acceleration levels that are believed to be exceeded with the same probability (or frequency). This is the reason why the spectrum is called uniform.

There are quite a few problems associated with this approach. First of all the spectral form is artificial and in many cases (except for the case of a single dominant source) its shape is different from a response spectrum of a real earthquake. Because many engineering methods (e.g. the so-called fragility method of EPRI $(1994,2002,2009)$ - the fragility function expresses the conditional probability of failure of a component for a given acceleration response spectrum) are explicitly using the shape information to assess the limit capacity of components of nuclear power plants an incorrect information on the spectral shape can lead to an incorrect assessment of the fragilities of components.

Secondly, this approach implicitly assumes (this is expressed by the term uniform) that the damaging impact of each of the contributing earthquakes (within the magnitude range between $m_{0}$ and $m_{u}$ ) has the same damaging impact. This is only true for certain design applications when a fully elastic response of a component during an earthquake is requested. In this case a force-based (mass multiplied by acceleration) design guarantees a robust performance. But a completely elastic response is not necessary for most of the structures, systems and components of a nuclear power plant. On contrary some limited inelastic behaviour is allowed from engineering and risk perspective and in many cases like for buildings it is even sufficient that a building collapse can be prevented. Therefore, some limited damage within required boundaries of functional performance is acceptable. Under these conditions a force-based design does not make sense. This is obvious from elementary school physics. For damaging something you have to perform work! And for performing work you have submit energy to the structure, system or component. The only sources of energy are the seismic input energy of the seismic waves arriving at the site and the potential energy of structure submitted to the seismic wave field. Acceleration level and spectral shape of the response spectrum define the amount of energy transferred to the structure. The seismic 
input energy defines the duration of the interaction length of hysteretic cycling of the structure, system or component. Therefore, for engineering and realistic risk applications (risk is dealing with damage) one needs the joint information of response spectrum, acceleration level and the earthquake strong motion duration. This joint information includes the correlation between these physical characteristics of an earthquake. High frequency accelerations caused by small near site earthquakes are completely unimportant under this perspective, but such earthquakes are just representing the dominant contributors to the results of a PSHA (Abrahamson et al. 2004). This can easily be confirmed by converting the deaggregation results of a PSHA into site intensities (or intensity factors in engineering terms) (Klügel 2009). Small near-site earthquakes may cause high accelerations but the intensities associated with such earthquakes are small or moderate (typically Intensity $\leq 7$ in EMS scale). Seismologists may not know this but such low intensity events do not provide a challenge to the robust design of modern nuclear power plants. Again, a PSHA possibly underestimates the seismic hazard because of the overestimation of the importance of small near site earthquakes.

\section{Summary and conclusions}

A detailed analysis of the root causes of the nuclear disaster at Fukushima and the actions taken by international and national organisations reveals that the key root causes are not yet addressed. This is especially true with respect to the hazard analysis for extreme natural events. It is still insufficiently understood that traditional probabilistic models based on the Poisson assumption are inadequate to calculate the frequency of rare extreme events. Only the IAEA launched in 2011 a program for the development of complementary safety assessment methods that avoid the explicit computation of the frequency of events and instead supports the development of tools for a better qualitative understanding of the strengths and vulnerabilities of nuclear power plants.

\section{References}

Abrahamson NA et al (2004) Probabilistic seismic hazard analysis for swiss nuclear power plant sites (PEGASOS Project), vol 1-6. NAGRA, Wettingen

Annaka T et al (2007) Logic-tree approach for probabilistic tsunami hazard analysis and its application to the Japanese coasts. PAGEOPH 164:S.577-S.592

Ayyub BM, Klir GJ (2006) Uncertainty modelling and analysis in engineering and the sciences. Chapman\&Hall, Boca Raton

Bolt BA (2004) Engineering seismology. In: Bozorgnia Y, Bertero VV (eds) Earthquake engineering. From engineering seismology to performance-based engineering. CRC Press, Boca raton, pp S.2-1-S.2-35

Cornell CA (1968) Engineering seismic risk analysis. Bull Seismol Soc Am 58:S.1583-S.1606

EPRI (1994) Methodology for developing seismic fragilities, TR-103959

EPRI (2009) Seismic fragility application guide update, TR-1019200

EPRI (2002) Seismic fragility application guide, TR-1002988

GRS (2013) Fukushima. Unfallablauf. Radiologische Konsequenzen. GRS, Köln

IAEA (2011) IAEA INTERNATIONAL FACT FINDING EXPERT MISSION OF THE FUKUSHIMA DAIICHI NPP ACCIDENT FOLLOWING THE GREAT EAST JAPAN EARTHQUAKE AND TSUNAMI Tokyo, Fukushima Dai-ichi NPP, Fukushima Dai-ni NPP and Tokai Dai-ni NPP, Japan 24 May-2 June 2011. IAEA, Vienna

INPO (2011) Special report on the nuclear accident at the Fukushima Daiichi Nuclear Power Station, INPO $11-05$

International Nuclear Safety Advisory Group (1996) Defence in depth in nuclear safety, INSAG-10. IAEA, Vienna 
Klügel J-U (2007) Error inflation in probabilistic seismic hazard analysis. Eng Geol 90:S.186-S.192

Klügel J-U (2008) Seismic hazard analysis-Quo vadis? Earth Sci Rev 88:S.1-S.32

Klügel J-U (2009) How to eliminate non-damaging earthquakes from the results of a probabilistic seismic hazard analysis (PSHA) — a comprehensive procedure with site-specific application. Nucl Eng Des 239:S.3034-S.3047

Klügel J-U (2011) Uncertainty analysis and expert judgement in seismic hazard analysis. Pure Appl Geophys 168:27-53

Lochbaum D et al (2013) FUKUSHIMA. The story of a nuclear disaster. The New Press, New York

Reiter L (1990) Earthquake hazard analysis. Issues and insights. Columbia University Press, New York

Senior Seismic Hazard Analysis Committee (SSHAC) (1997) Recommendations for probabilistic seismic hazard analysis: guidance on uncertainty and use of experts, NUREG/CR-6372. NRC, Washington 